\title{
Os Tupí em Rondônia: diversidade, estado do conhecimento e propostas de investigaçãa ${ }^{1}$
}

\author{
Felipe Ferreira Vander Velden ${ }^{2}$
}

\begin{abstract}
Resumo
A região do alto rio Madeira e seus formadores - que corresponde ao estado de Rondônia e às áreas vizinhas do noroeste do Mato Grosso, sul do Amazonas e oriente boliviano - apresenta uma notável diversidade de populações indígenas falantes de línguas de várias famílias do tronco Tupí (Tupí-Guaraní, Arikém, Ramaráma, Puruborá, Mondé, Mundurukú, Tuparí e Mawé). Esta riqueza foi apontada por vários autores que refletiram sobre essa região, tendo-a visitado ou não. As advertências destes pesquisadores, contudo, não garantiram uma continuidade no interesse pela etnologia indígena na bacia do alto Madeira, e não resultaram em uma produção consistente e integrada que buscasse desvendar as dinâmicas atuais e históricas dessa diversidade. Em resumo: nosso conhecimento das culturas Tupí em Rondônia e adjacências é pobre, disperso e pouco sistematizado. É tarefa necessária que a etnologia indígena dos Tupí na bacia do alto Madeira tome um rumo coeso, abrindo espaços de interlocução e integrando seus achados, com vistas a incrementar a produção antropológica e histórica acerca dessas populações e a refinar nosso conhecimento sobre cada uma de suas culturas, além dos cenários interétnicos e das trajetórias históricas locais, regionais e mesmo suprarregionais. Este artigo tem como objetivo mapear a produção etnológica sobre os grupos Tupí na região aqui definida como "Grande Rondônia”, e apontar algumas possibilidades e estratégias de pesquisa que poderão vir a incrementar o conhecimento sobre a riquíssima diversidade social, cultural e linguística da região.
\end{abstract}

Palavras-chave: Antropologia, Etnologia, povos Tupí, Amazônia, Rondônia.

\begin{abstract}
The region of the Madeira river basin and its tributaries - which corresponds to the Brazilian state of Rondônia, and the adjacent regions of northwestern Mato Grosso, southern Amazonas, as well as the eastern Bolivian lowlands - shows a remarkable diversity of indigenous peoples speaking languages of several linguistic families belonging to the Tupian linguistic stock (Tupí-Guaraní, Arikém, Ramaráma, Puruborá, Mondé, Mundurukú, Tuparí, and Mawé). This linguistic and cultural wealth was pointed out by many travelers who have written on that region having been there or not. These researchers' advises, notwithstanding, did not
\end{abstract}

\footnotetext{
${ }^{1}$ Este texto foi apresentado no Simpósio X - Os Tupí no alto Madeira: avanços no conhecimento da etnologia de Rondônia, realizado no âmbito do III Encontro sobre Línguas e Culturas Tupí, ocorrido na Universidade de Brasília entre 20 e 22 de outubro de 2010. Agradeço a Ana Suelly A. Câmara Cabral a acolhida dessa mesa no evento Tupí, e a Estevão Rafael Fernandes, Edmundo Peggion, Giovana Tempesta, Edwin Reesink e Aryon Dall'Igna Rodrigues pelo apoio, comentários, críticas e sugestões.

2 Professor do Departamento de Antropologia - IFCH - UNICAMP. Endereço residencial: Rua Humberto Pescarini, 633, Centro, Vinhedo-SP, CEP: 13.280-000. Telefones: (19) 3826-2856 / (19) 8123-2608. Endereço eletrônico: felipevelden@yahoo.com.br
} 
warranted a continuous interest on the ethnological understanding of the Madeira river basin, and did not produce a consistent attempt to understand the region's present and historical dynamics. In brief: knowledge about Tupian-speaking peoples in Rondônia and southwestern Amazonia is still poor, dispersed and low-systematized. To develop ethnological studies on the Tupian peoples of the Madeira river basin is therefore an urgent task, opening discussion efforts and integrating research findings to increase our anthropological and historical knowledge on such populations, including inter-ethnic settings and historical trajectories in local, regional, and supra-regional levels. This article aims to map ethnological knowledge on the Tupí speaking peoples in the regions here called "Great Rondônia" and to suggest some new research strategies and objectives designed to develop our understanding of its extremely rich social, cultural, and linguistic diversity.

Keywords: Anthropology, Ethnology, Tupian speaking peoples, Amazonia, Rondônia.

\section{Introdução: uma "Grande Rondônia"}

Este trabalho pretende ser um convite para o incremento da investigação etnológica entre os povos indígenas de língua Tupí localizados, histórica e atualmente, em Rondônia. Divide-se em três seções: a primeira destaca a diversidade dos povos indígenas naquela região, riqueza cultural, social e histórica, que por si só justifica a necessidade de mais pesquisas entre essas populações; a segunda apresenta um balanço da produção etnológica acerca desses povos, buscando delinear minimamente o estado de nossos conhecimentos na etnologia dos povos indígenas da região. Se não exaustivo, o levantamento aqui realizado buscou contemplar, em grandes linhas, a qualidade dos trabalhos até agora empreendidos e a relativamente extensa bibliografia existente; ${ }^{3}$ e a terceira, finalmente, apresenta uma justificativa teórica que, parece-me, fundamenta a importância e a centralidade do aprofundamento das pesquisas com as populações nativas do sudoeste da Amazônia - das várias filiações linguísticas - para o desenvolvimento da etnologia sul-americana como um todo.

Antes, porém, é necessário esclarecer o que estamos denominando por Rondônia. Não tratamos aqui unicamente do estado de Rondônia, ainda que ele esteja no centro de nossos interesses. Em termos geográficos, estamos nos referindo à região que compreende, além de Rondônia, também o noroeste do Mato Grosso, o sudeste do Amazonas e ainda o nordeste do Oriente boliviano - ou seja, grosso modo, a área drenada pela bacia do alto rio Madeira e seus formadores - Mamoré, Guaporé e Beni - e afluentes. Em outros termos,

\footnotetext{
3 Qualquer referência que tenha escapado na bibliografia aqui apresentada será considerada em levantamentos futuros.
} 
estamos considerando o território compreendido entre os rios Tapajós (a leste) e Madre de Dios (a oeste), o alto Madeira (ao norte) e o médio-baixo Guaporé (ao sul), zona que poderíamos denominar de "Grande Rondônia".

Esta delimitação contrasta com outras propostas de definição de áreas etnográficas do Brasil. Por exemplo, nós propomos agrupar duas das áreas culturais indígenas definidas por Eduardo Galvão (1979), a do "Guaporé" (área III) e a do "Tapajós-Madeira" (área IV), esta, pelo menos, em sua porção meridional. $\mathrm{O}$ mesmo se diga quanto à divisão empregada pelo Instituto Socioambiental (ISA 2006), que também mantém separadas as áreas denominadas "Rondônia" (área XI) e "Tapajós-Madeira" (área VII), as quais propomos integrar, mas apenas parcialmente, o médio-baixo Madeira como parte do que aqui chamamos "Grande Rondônia", pela presença ali dos grupos Tupí Tenharín, Diahói e Parintintín (além dos Torá, não-Tupí).

Nossa proposta contrasta, ainda, com a de Júlio Cézar Melatti (s. d.), que dividiu a região que nos interessa em pelo menos quatro áreas etnográficas distintas, a saber: "Mamoré-Guaporé", "Aripuanã", "Amazônia Centro-Meridional" e "Mojos e Chiquitos". Os critérios utilizados pelo autor são sólidos e bem fundamentados, e têm o mérito de considerar não apenas o território brasileiro, como fez Galvão e faz o Instituto Socioambiental. Entretanto, aqui estamos levando em conta sugestões - a partir de Eduardo Viveiros de Castro e discutidas na terceira seção deste texto - de que a zona de transição ecológica entre Amazônia e Cerrado, que parece ser, como veremos, zona de transição de formas sócio-cosmológicas, e, portanto, pode ser "boa para pensar" as sociedades e culturas das terras baixas sulamericanas. Considerando a fragmentação interna que Melatti efetua da porção ocidental desta faixa de transição (que estamos denominando "Grande Rondônia”), optamos por uma outra proposta, visto que um dos objetivos de nossa pesquisa é o de agregar os trabalhos que tratam de populações que habitavam as calhas dos formadores do rio Madeira e, hoje, gravitam em torno da oferta de recursos e serviços que se originam no estado de Rondônia. Mesmo esta delimitação do oeste da zona transicional não nos deve impedir de refletir sobre suas relações com as populações que ocupam o centro e o leste da mesma grande região.

Nossa proposta também difere daquela mais recente, de Marco Paulo Schettino (2003), destinada a dinamizar os trabalhos de reconhecimento dos territórios indígenas do Brasil a partir da caracterização precisa de áreas etnográficas e da sistematização dos conhecimentos históricos e antropológicos 
acumulados para cada uma das 17 áreas propostas - conhecimentos que devem ser a base para a construção dos laudos técnicos a partir dos dados já organizados regionalmente. O autor propõe, como área XVI, "Rondônia", "cuja superfície engloba praticamente todo o estado de Rondônia e pequena faixa do noroeste do estado de Mato Grosso [e] caracteriza-se pela alta diversidade étnica" (Schettino 2003:39-40). Nossa proposta aqui subscreve este território, mas busca incluir o extremo sul do que Schettino (2003, 3233) denomina "eixo Madeira" da área "X - Madeira-Tapajós", a saber, os povos Tenharín, Torá, Apurinã, Diahói, Pirahã, Parintintín e Múra localizados no alto Madeira, na fronteira entre os estados do Amazonas e Rondônia. As afinidades culturais entre alguns desses grupos e outros povos mais ao sul, em Rondônia (os Tupí-Kawahíwa), além dos múltiplos vínculos históricos e políticos destes grupos com Rondônia (indígena e não-indígena) parecem autorizar essa sugestão.

Nosso foco aqui, portanto, é o imenso território que faz a transição entre os biomas da Amazônia (ao norte) e do Brasil Central (ao sul). Esta é uma zona de transição ecológica, que abriga numerosas sociedades que parecem combinar formas cosmológicas e morfológicas tanto amazônicas quanto centro-brasileiras, configurando, também no sentido etnológico, uma espécie de zona-tampão transicional entre as sócio-cosmologias Tupí amazônicas e as Macro-Jê no Brasil Central. Esta ampla faixa de terra, orientada horizontalmente no sentido leste-oeste, vai aproximadamente dos Karajá e Tapirapé, no vale do Araguaia (limite leste), até a fronteira Pano (a oeste), já nos limites entre os atuais estados de Rondônia e Acre; inclui, ainda, a região de terras baixas nos limites entre Rondônia e a República da Bolívia. O território etnográfico que estamos denominando "Grande Rondônia" compreende, grosso modo, aos limites ocidentais desta zona de transição, deixando de lado o alto Xingu e o que há a leste, e sem adentrar nos domínios dos povos de língua Pano e de seus estudiosos. Tal recorte se justifica não apenas porque os contatos (históricos e etnológicos) entre nossa Rondônia e as áreas Pano e Xinguana ainda precisam ser melhor compreendidos, mas também por se tratar das áreas excepcionalmente bem caracterizadas do ponto de vista etnográfico, dispondo de quantidade significativa de pesquisas, consolidado corpo de especialistas e um forte debate interno aos respectivos campos ("panólogos" e "xinguanólogos", se assim posso me expressar).

Uma delimitação mais recente, e em certo sentido coincidente com a que estamos sugerindo aqui, foi feita por Crevels e van der Voort (2008) em sua definição da região do Guaporé-Mamoré como "área linguística" 
(linguistic area). Os dois autores consideram a imensa área drenada pelos rios Mamoré, Guaporé, Beni e Madre de Dios (e seus afluentes), nos limites entre Bolívia, Brasil e (em menor medida) Peru (Crevels \& van der Voort 2008:157). A proposta - que se funda sobre extensa recensão das fontes linguísticas, históricas e etnográficas existentes - inclui os grupos de língua Pano meridionais (Chacobo, Pacaguara, Yaminahua e Kaxarari) e alguns dos povos do leste mato-grossense (Rikbatsa, Paresí e EnaweneNawê), mas deixa de fora, mais uma vez, os grupos Tupí-Kawahíwa do alto Madeira. Tendo-se em consideração que outros Tupí-Kawahíwa em Rondônia foram considerados (Júma, Uru-eu-uau-uáu, Amondáwa e Karipúna), não vemos razão para separá-los. O mesmo se diga dos Torá, não-incluídos, e separados de outros Txapakúra, que foram, no entanto, considerados (Warí, Migueleño e outros).

A área definida pelos dois linguistas corresponde, em linhas gerais (e consideradas as observações acima feitas), à que estamos considerando como "Grande Rondônia", em função das articulações culturais e históricas que podem ser minimamente traçadas entre as diferentes sociedades que ali vivem ou viviam - articulações que foram notadas - mas não, lamentavelmente, descritas em profundidade - por vários autores que viajaram pela região e que sobre ela escreveram, como Rondon (1916), Roquette-Pinto (1935), Caspar (1953a), Lévi-Strauss (1948a, 1948b, 1996) e Meireles (1984, 1989), entre outros. Tais relações e articulações culturais, sociais, políticas, econômicas e históricas entre distintas sociedades foram muito bem demonstradas por Miguel Menendez (1981-1982, 1984-1985, 1992)4 para os povos no médio e baixo Madeira - situados imediatamente ao norte de nossa área de interesse -, e não existem razões para negar que tal panorama também se verificava nos vales do alto Madeira, Guaporé-Mamoré e afluentes (de todo modo, as pesquisas, que pretendemos tenham origem nesta proposta, devem vir a aguçar nossa compreensão das relações entre os povos na região, aumentando a precisão dos limites que ora apenas esboçamos).

É evidente que esta nossa demarcação de limites é arbitrária, posto que as relações entre as populações na região não parecem estar totalmente ou majoritariamente voltadas para seu interior, como parece acontecer em certas áreas etnográficas nas terras baixas, como o alto Xingu ou o alto rio Negro (Franchetto \& Heckenberger 2001; FOIRN \& ISA 2000). Não obstante, por um lado, mesmo para estas áreas relativamente bem delimitadas há algum grau de arbitrariedade na definição de limites, como bem perceberam os

\footnotetext{
${ }^{4}$ Ver também Cypriano (2007).
} 
próprios autores que se dedicam à definição de "áreas etnográficas" ou "culturais" (Melatti s. d). Por outro lado, as poucas informações disponíveis sobre as populações indígenas no sudoeste da Amazônia parecem indicar que elas partilham de certas experiências históricas pré- e pós-coloniais comuns, algo apontado pelos (poucos) estudos até agora realizados na região. Assim, Denise Meireles (1989) indicou os intensos trânsitos de pessoas, mercadorias e animais através da fronteira luso-espanhola do Guaporé no século XVIII. Assim, também, Gilio Brunelli (1989) destacou uma orientação para o oeste dos grupos Tupí-Mondé no Aripuanã. Identidades linguísticas, culturais e históricas conectam os povos Tupí-Kawahíwa que se espalham pelo centronorte de Rondônia, extremo norte do Mato Grosso e sul do Amazonas (Kracke 2007a; Sampaio 2001). Qualquer um que visite Porto Velho reconhece que, como maior centro urbano regional, a cidade polariza grande parte das demandas das populações nativas desta grande área, incluindo aquelas originadas fora do estado de Rondônia.

Aqui estaremos, portanto, considerando esta "Grande Rondônia" mais ou menos no espírito daquela "Rondônia" de Roquette-Pinto (1935) - como uma unidade, em função das relações mais ou menos permanentes, das trajetórias histórico-culturais comuns e dos alinhamentos políticos recentes - todos afetados por macro-processos históricos, sociais e políticos semelhantes (cf. Santos-Granero \& Barclay 1994) -, além das proposições teóricas que destacam a importância estratégica desta zona-tampão entre a floresta amazônica e o cerrado centro-brasileiro para o estudo das sociedades e culturas nativas da América do Sul, tema ao qual voltaremos na última seção deste texto.

Para o caso dos grupos Tupí, a delimitação é mais simples: trata-se do conjunto de grupos, pertencentes a várias famílias linguísticas distintas no interior do tronco Tupí, que se concentra na bacia dos formadores do rio Madeira, maior afluente do rio Amazonas, no sudoeste da Amazônia. Estão, assim, relativamente separados de outros agrupamentos de povos Tupí ao norte, ao sul e a leste. Esta região também se define por concentrar várias famílias do tronco Tupí (Tupí-Guaraní, Arikém, Mondé, Ramaráma, Tuparí e Puruborá), algumas exclusivamente localizadas ali (caso das cinco últimas citadas: cf. Rodrigues 1964, 1986:42) sendo, por esta razão, apontada por Rodrigues (1999) como centro de origem do próprio tronco linguístico Tupí e ponto de partida para sua posterior difusão dessas línguas e culturas para outras áreas do continente (Rodrigues 1964; Urban 1992; Noelli 1998)5.

\footnotetext{
5 Vale advertir que, aqui, estamos conscientes de que os povos Tupí-Guaraní na Bolívia não estão
} 
Nesse sentido, há de se considerar a proposição de Eurico Miller (2009) - falando a partir da perspectiva da arqueologia - sobre a origem do tronco Tupí, e de diversas famílias em seu interior, no que denomina "Mesopotâmia Guaporé-Madeira-Aripuanã", grande área que agrega a porção do território brasileiro que reclamamos na nossa definição de uma "Grande Rondônia", embora deixe de fora as terras baixas da Bolívia. A questão, aqui, é definir se o rio Guaporé é, de fato, uma fronteira suficientemente significativa para demarcar as trajetórias das populações nas suas duas margens: mais pesquisas arqueológicas, antropológicas, históricas e linguísticas deverão aprofundar-se neste ponto. Aqui estamos subscrevendo a proposta de Crevels \& van der Voort (2008) de tratar conjuntamente ambos os lados da fronteira, além de apostar nos trânsitos efetivamente existentes através desta fronteira, talvez por demais "engessada" pela historiografia que mantinha separadas e estanques a parte luso-brasileira e a parte hispano-boliviana do território (Meireles 1989). De mais a mais, uma definição mais abrangente permite ampliar o diálogo com diferentes pesquisadores, a partir do qual poderemos, paulatinamente, refinar estas primeiras sugestões ${ }^{6}$.

\section{Balanço da produção etnológica sobre os Tupí na "Grande Rondônia"}

A região que estamos denominando de "Grande Rondônia" apresenta uma notável riqueza cultural e diversidade linguística, especialmente no interior do tronco Tupí. Ali encontramos representantes de seis das 10 famílias que compõem este tronco: isto, aliado à presença de línguas de várias outras famílias linguísticas, caracteriza a área como uma das zonas de maior diversidade linguística em todo o continente sul-americano (Rodrigues 1964; Urban 1992; Crevels \& van der Voort 2008).

diretamente relacionados aos grupos da mesma família linguística na outra margem do Guaporé, mas provêm de antigas migrações provenientes do sul (Rodrigues 2007). Não obstante, aqui estamos menos preocupados com as relações genéticas entre línguas/culturas, mas com diferentes modalidades de relações, incluindo as históricas (também pós-coloniais), comerciais e políticas.

${ }^{6}$ Será preciso também, talvez, ampliar nossa área de investigação no sentido leste, para incluir também os grupos Tupí do centro-leste de Mato Grosso (os Apiaká) e do sul do Amazonas e do Pará (os Mundurukú e os Sateré-Mawé, além de outros grupos extintos). As relações históricas destes últimos com os Tupí-Kawahíwa, demonstradas em detalhes por Miguel Menéndez (1981-1982, 1984-1985, 1992), apontam para a provável proficuidade desta inclusão, e aqui não estamos considerando estes povos porque a produção etnológica sobre eles é razoavelmente extensa e os dados disponíveis sobre eles remontam, pelo menos, ao século XVII; não obstante, deverão ser considerados futuramente, na paulatina ampliação do diálogo com territórios vizinhos da nossa "Grande Rondônia". O caso Apiaká também necessita apreciação: trata-se de um povo pouco estudado pela etnologia (Tempesta 2009) e, tendo em vista os limites apresentados aqui, fora das áreas delimitadas por Crevels \& van der Voort (2008) e por Miller (2009), que estamos considerando como definidores de nosso território. Contudo, o diálogo com o material (etnográfico, histórico e linguístico) existente sobre este povo (e outros grupos Tupí nas circunvizinhanças) poderá vir a alterar nossas expectativas preliminares. 
Esta notável riqueza linguística também se verifica quanto à cultura e à história das sociedades indígenas dali. Com efeito, vários autores destacaram a diversidade de culturas, e mesmo notaram o valor estratégico do estudo da região para a compreensão das terras baixas sul-americanas em sua totalidade (Lévi-Strauss 1948a; Meireles 1989, 1991; Urban 1992; Crevels \& van der Voort 2008). Atualmente, a região que definimos como Rondônia abriga cerca de 60 povos e aproximadamente 50 línguas nativas, muitos deles ainda pobremente conhecidos; povos falantes de línguas Tupí são pelo menos 22 nesta região. Esta diversidade cultural se faz acompanhar, ainda, de uma variedade também significativa de situações sócio-históricas vividas atualmente por essas populações: encontramos, ali, desde povos em isolamento voluntário, sem contato (como é o caso dos vários pequenos grupos Tupí-Kawahíwa que perambulam pelo noroeste mato-grossense (Cartagenes \& Lobato 1991) ou do grupo isolado na Reserva Biológica do Guaporé que se supõe ser Sirionó, de língua Tupí-Guaraní), até povos que se pode dizer "emergentes", que se julgava extintos, mas vêm reaparecendo no cenário étnico regional nos últimos anos, como é o caso dos Puruborá em Rondônia (CIMI-RO 2002).

Os estudos linguísticos, pois, avançam em ritmo acelerado, não apenas no tocante á descrição de idiomas isoladamente, mas também no que se refere à composição de um quadro regional e nas contribuições do conhecimento desta região para a composição de um panorama continental. Lamentavelmente, o mesmo não se pode dizer da produção antropológica sobre as populações indígenas na área, ainda muito incipiente, pouco sistematizada e com frágil diálogo interno e externo; embora conversando com as teorias antropológicas mais recentes, a etnologia indígena na "Grande Rondônia" carece de um quadro regional minimamente estabelecido - o que se percebe na nossa própria dificuldade em delimitar esta região - e ainda não realizou um esforço concentrado de intercâmbio de informações com vistas à configuração de um quadro cultural e histórico que permita estratégias comparativas ou uma reflexão detalhada dos processos macrosociais que abarcam esses povos em conjunto. Ou seja, conhecemos pouco das sociedades indígenas na região, e menos ainda das relações entre elas, muito porque conhecemos mal nós mesmos, que estamos fazendo etnologia em Rondônia. Temos algumas monografias de fôlego e excelente qualidade, mas falta, ainda, a composição de um quadro regional, tal como existe para o alto Xingu e o alto rio Negro, áreas etnográficas que dispõem de uma produção razoavelmente contínua - ainda que variada em termos de sua qualidade - 
de conhecimentos antropológicos há pelo menos um século7. Para o caso da nossa "Grande Rondônia", alguns poucos estudos oferecem vislumbres das múltiplas relações entre populações distintas em certos territórios restritos, como os de Gilio Brunelli (1989) para os grupos Tupí-Mondé, de Mauro Leonel (1996) para a fronteira Tupí-Txapakúra, e de Denise Meireles (1991) para os grupos do que ela denominou "área cultural do marico", nos rios Branco, Colorado e Mequéns. Não obstante, muito trabalho ainda resta por ser feito e pode-se bem reconhecer esta fragilidade no caso dos povos Tupí, que nos interessam particularmente aqui.

Procedamos, então, a um breve balanço da produção etnológica regional. Desde já, vale a advertência de que esta recensão não pretende ser completa, mas apenas indicar o que temos de mais substancial ou de acesso mais fácil - não tenho, por exemplo, clareza da dimensão de uma produção local (na Universidade Federal de Rondônia e outras localizadas na área em estudo), embora não acredite ser falso afirmar que ela ainda é pequena; da mesma forma, ainda estamos tomando contato com os estudos realizados entre povos Tupí no leste da Bolívia, sobretudo no que concerne a etnólogos bolivianos ou ao material publicado exclusivamente naquele país, cujo acesso ainda é, infelizmente, precário.

Dois conjuntos de povos Tupí destacam-se entre os mais bem estudados pela etnologia regional, e isso nas duas extremidades latitudinais da área em análise. Ao norte, Lévi-Strauss (1948b, 1996[1955]), Curt Nimuendajú (1924, 1948) e Joaquim Gondim (2001[1924]) colocaram no mapa etnográfico os Tupí-Kawahíwa (Tupí-Guarani). Nunes Pereira $(1980,2007)$ também recolheu e organizou informações preciosas sobre os Kawahíwa-Parintintín. Depois desses pioneiros tivemos os estudos seminais de Waud Kracke (1978, 1984, 1990a, 1990b 1992, 2007), e as contribuições avançadas por Miguel Menéndez

\footnotetext{
7 O que quero dizer aqui é que qualquer monografia sobre uma determinada população indígena no alto Xingu e no alto rio Negro, e mesmo nas Guianas e no interior do conjunto Pano na fronteira BrasilPeru-Bolívia, pode se utilizar de amplo material produzido por estudiosos trabalhando com vários povos na mesma região (ou da mesma família linguística), além de dispor de documentação histórica em razoável quantidade e qualidade; isso torna os trabalhos individuais espaços de discussão com a literatura colateral disponível, ajudando a compor, deste modo, quadros regionais mais e mais refinados. Os estudos feitos até o momento com os povos indígenas na "Grande Rondônia" ainda dispõem de pouco material com o qual dialogar, especialmente no tocante a trabalhos de fôlego realizados com o mesmo grupo ou com populações vizinhas. Na minha tese de doutorado (Vander Velden 2010:4659), por exemplo, busquei reconstituir a trajetória dos Karitiána desde ao menos a segunda metade do século XIX. Tive, para tanto, que me contentar com a historiografia pobre disponível para a região e alguns poucos estudos sobre povos vizinhos (os Uru-eu-uau-uáu e os Warí), ainda que os Karitiána mencionassem frequentemente, na sua história, os contatos (belicosos) com sociedades que viviam nas cercanias de seu território.
} 
(1987, 1989), incluindo seu trabalho acerca da história das populações indígenas no vale do Madeira (Menéndez 1981-82, 1984-85) que, se não se limitaram à área aqui definida, trouxeram aportes significativos para a compreensão da articulação histórico-cultural das sociedades nativas imediatamente ao norte de nossa Rondônia. Edmundo Peggion (1995, 1996, 1998, 2004, 2005, 2007a, 2008, 2009), com seu trabalho entre os Tenharín, é o principal continuador das pesquisas com os Tupí-Kawahíwa. Angela Kurovski (2005) defendeu dissertação de mestrado recente sobre os Kawahíwa-Parintintín. Mauro Leonel (1996) investigou a trajetória do contato e das relações inter-étnicas dos Uru-eu-uau-uáu, mas este povo ainda continua muito pouco conhecido etnologicamente. Praticamente desconhecidos pela antropologia ainda estão os Amondáwa - uma breve coletânea de mitos foi publicada por Wany Sampaio et al. (2004), além de um pequeno volume com dados etnográficos (Silva 1997) e um artigo sobre onomástica (Peggion 2007b) -, os Juma - dos quais conhecemos alguma coisa da trágica história do contato (Cornwall 2003) - e os Karipúna, povo cuja presença está fortemente marcada na história de Rondônia, posto que estavam na rota de colisão da Estrada de Ferro Madeira-Mamoré, e sobre os quais praticamente nada sabemos da perspectiva etnológica. Iniciamse no momento as pesquisas sobre os Piripkúra, outro grupo Tupí-Kawahíwa no noroeste mato-grossense (podem existir outros povos aparentados na região), e os dados aportados poderão trazer novas perspectivas sobre as relações internas ao conjunto Tupí-Kawahíwa e destes com grupos de língua Tupí mais a leste.

Ao sul, temos um bom conjunto de trabalhos antropológicos com os povos de língua Tupí-Mondé. Betty Mindlin (1985) publicou sua já clássica monografia sobre os Suruí-Paiter, fruto de sua pesquisa de doutorado (Mindlin 1984a), além de muitos artigos (1981, 1984b, 1984-85, 1989, 1990, 1992, 1993a, 1994, 1995a) e de coletâneas de mitos e conhecimentos dos Suruí (1996, 2006a) e também dos Gavião-Ikolen (2001), além de seleções de mitos provenientes de diferentes povos Tupí-Mondé (Mindlin 1997, 1999, 2006b). Os Cinta-Larga foram estudados etnograficamente por Richard Chapelle (1982), Carmem Junqueira (s.d., 1984, 1984-85, 2002) e, anos depois, por Priscilla Ermel (1988), por João Dal Poz Neto (1991, 1993, 1998, 2004, 2010) e por Laura Freitas (1996). Gilio Brunelli publicou excelente tese (1989) e vários artigos sobre os Zoró (Brunelli 1985, 1987a, 1987b, 1988a, 1988b, 1990); os Zoró também foram pesquisados por Sophie Cloutier (1987, 1988a, 1988b). Lars Lovold (1980, 1987) realizou pesquisas comparativas entre os Gavião-Ikolen (Gavião de Rondônia) e os Zoró. Os Gavião-Ikolen vêm sendo estudados recentemente por Ivaneide Cardozo 
(2006), e há alguns trabalhos que investigam a situação social e a trajetória dos dois grupos na Área Indígena Igarapé Lourdes (os Gavião-Ikolen e os Arára Káro, estes Tupí-Ramaráma), focalizando sobretudo a relações destes grupos com os projetos de barramento do rio Machado (Forseth \& Lovold 1991; Nóbrega 2008). Dos Aruá temos tão-somente alguns mitos coletados por Betty Mindlin (1995b), dispersos entre mitos de vários outros povos, e as notas gerais de Denise Meireles (1991) sobre as distintas populações no médio vale do rio Guaporé.

Embora existam estudos monográficos que permitem que conheçamos razoavelmente os povos Tupí-Kawahíwa (Tupí-Guaraní) e Tupí-Mondé na "Grande Rondônia", estamos distantes de uma descrição detalhada e exaustiva destas culturas, e ainda mais afastados de sínteses que dêem conta das inter-relações históricas e culturais entre elas, no interior de cada um dos conjuntos linguísticos e entre estes e as populações vizinhas, indígenas e não-indígenas.

Os demais povos Tupí em Rondônia estão, infelizmente, em estágios de investigação antropológica ainda mais incipientes. Creio serem os Karitiána os mais bem conhecidos. O casal de linguistas David e Rachel Landin produziu alguns trabalhos de interesse antropológico (D.Landin 1979; R.Landin 1985, 1989), destacando-se a tese de Rachel sobre o parentesco neste grupo. Em seguida, os sistemas de classificação social Karitiána foram retomados por Carlos Frederico Lúcio (1996; ver também 1998) em dissertação de mestrado. Liliam Moser coletou material de qualidade para a análise da história, do conhecimento mítico e das relações inter-étnicas dos Karitiána (Moser 1993). Felipe Vander Velden (2004, 2005, 2007, 2008, 2010a, 2010b) vem trabalhando com diversos aspectos da relação entre os Karitiana e o mundo dos brancos, e aguarda-se ansiosamente a tese de doutorado de Andréa Oliveira Castro sobre relações de parentesco e substância neste povo de língua Tupí-Arikém (ver Castro 1996).

Os pequenos grupos Tupí localizados na bacia do rio Guaporé - Tuparí, Makuráp, Wayurú, Sakyrabiát, Akuntsú (família Tuparí) e Aruá (família Mondé $)^{8}$ - são ainda menos conhecidos pela etnologia. Franz Caspar nos legou preciosas descrições dos Tuparí nos anos de 1950 (Caspar 1952, 1953a), e uma monografia de grande relevância para o conhecimento deste povo (Caspar 1975), além de vários artigos (Caspar 1953b, 1955a, 1955b, 1956$58,1976[1957])$ que, inclusive, fazem menção a outros povos vizinhos dos

\footnotetext{
${ }^{8}$ Naturalmente, há uma miríade de povos extintos, sobre os quais sabemos nada ou muito pouco.
} 
Tuparí. Emilia Snethlage $(1937,1939)$ também deixou uns poucos materiais sobre esses grupos, vários deles de reduzida população atualmente. Depois dela tivemos apenas mitos Tuparí coletados por Betty Mindlin (1993b), que também organizou um volume de mitos recolhidos entre grupos Tupí e nãoTupí na região do Guaporé (Mindlin 1995b; ver também Mindlin 2006b, 2010); o artigo seminal de Denise Meireles (1991) a respeito do "complexo do marico" (um tipo de cesto) - que inclui os povos não-Tupí na região; e a recente dissertação de mestrado de Nicole Pinto (2009) sobre os Wayurú.

Sobre as populações de língua do tronco Tupí no oriente boliviano, apenas os Sirionó contam com um estudo detalhado, a clássica e controversa monografia de Allan Holmberg (1969). Allyn Stearman reavaliou as conclusões de Holmberg acerca dos Sirionó (Stearman 1984, 1987) e vem trabalhando com os Yuquí, outro grupo Tupí-Guaraní nas terras baixas bolivianas (Stearman 1989, 2006). Jürgen Riester (1977) publicou breve trabalho sobre os Guarasu'we, outro povo Tupí-Guaraní da Bolívia. Embora não tenhamos um quadro mais completo da produção etnológica a respeito dos povos de língua Tupí no leste da Bolívia, aparentemente muito trabalho ainda precisa ser feito nas terras Tupí, na república vizinha.

Devemos evocar, de passagem, as pesquisas de qualidade desenvolvidas entre vários grupos Tupí em Rondônia - notadamente entre os Karitiána e os Tupí-Mondé - por pesquisadores ligados à antropologia da saúde, à bioantropologia, à ecologia humana e a várias ciências biomédicas. Esses trabalhos vêm aguçando nossa compreensão sobre os perfis atuais e históricos da saúde e da enfermidade entre essas populações, além de aportarem importantes dados - cujo interesse para a etnologia regional revela-se bastante significativo - sobre sistemas médico-terapêuticos, etiológicos e nosológicos nativos, histórico do contato, migrações, práticas produtivas, conhecimento botânico, zoológico e técnico e formas de adaptação aos novos contextos trazidos com o estabelecimento das relações intensivas e permanentes com os brancos. A produção dos pesquisadores vinculados a este campo é enorme, e ele tem bastante força no cenário científico rondoniense - haja vista a existência do Centro de Estudos em Saúde do Índio de Rondônia (CESIR), vinculado à Universidade Federal de Rondônia (UNIR) e à Fundação Oswaldo Cruz (FIOCRUZ), e sediado em Porto Velho. Impossibilitados, assim, de elencar aqui toda a produção das áreas biomédica e bioantropológica, sugerimos os trabalhos pioneiros de Carlos Coimbra Jr. (1989) e Ricardo Ventura Santos (1991) para uma boa introdução a estes campos de estudos. 
Pesquisas comparativas, que busquem pensar as relações entre cosmologias e organizações sociais indígenas na "Grande Rondônia", são ainda mais escassas, e a maioria delas extravasa os limites da região que pretendemos circunscrever, buscando articular dados oriundos de outras populações, com vistas não a consolidar uma região etnograficamente específica, mas a repensar conjuntos mais amplos, tais como a Amazônia e o Brasil Central (e a zona de transição entre eles), ou os grupos Tupí e Macro-Jê, por exemplo; assim, Eduardo Viveiros de Castro (2002) emprega o material rondoniense (incluindo noroeste do Mato Grosso e Oriente boliviano) em suas reflexões gerais sobre as terras baixas sul-americanas. De modo menos ambicioso, Carolina Pucu Araújo (2002) esboçou uma sistematização das relações entre sistemas de parentesco Tupí, discutindo com mais vagar os dados Cinta Larga e Karitiána. E Carmem Junqueira (2002) propôs uma comparação das relações de gênero entre os Cinta Larga e os Kamayurá no Xingu, extremidade leste da zona de transição amazônicocentro brasileira. Honrosas exceções, ao buscar articular um universo de povos geograficamente próximos e intensamente relacionados histórica e culturalmente, são o livro de Brunelli (1989) sobre os Tupí-Mondé e o artigo isolado de Denise Maldi Meireles (1991) sobre os grupos das terras indígenas Rio Branco e Rio Guaporé. Ou seja, falta-nos ainda uma boa visão do conjunto regional que buscamos definir aqui.

A carência deste panorama geral é ainda mais acentuada pela fraqueza da historiografia de Rondônia, no geral uma região ainda parcamente conhecida em termos históricos. Estamos ainda muito dependentes do monumental trabalho de Vitor Hugo (1959), publicado pela primeira vez em 1959! E as pesquisas atuais em larga medida falham em articular os processos e eventos históricos com a maciça presença indígena, registrada em migalhas, em cada um deles. O fato histórico mais conhecido da história regional - a construção da Ferrovia Madeira-Mamoré no início do século $\mathrm{XX}$ - teve crucial envolvimento, e mesmo participação direta, dos grupos conhecidos por Karipúna e Arára, que viviam nos arredores da obra e que foram duramente atingidos por ela; não obstante os estudos sobre a EFMM raramente mencionem os índios, e só Mauro Leonel (1996) tenha recolhido algumas dramáticas histórias daqueles momentos no início do século passado.

Somente Denise Meireles (1984) buscou sistematizar, em grandes linhas, a história indígena em Rondônia, com particular atenção ao vale do Guaporé (1989). Essa autora buscou recolher tudo o que se sabia da história dos povos indígenas na região até o final dos anos de 1980. Desde então, 
contudo, pouco foi acrescentado, sobretudo no tocante a investigações que abordem as trajetórias de grupos específicos e suas relações com populações vizinhas (indígenas e não-indígenas), além de suas próprias perspectivas sobre essa história, mais ou menos como Mauro Leonel esboçou para os Urueu-uau-uáu (1996) e Aparecida Vilaça (2006) fez, recentemente, e de modo bastante detalhado, para os diversos subgrupos Warí (Txapakúra).

Da mesma forma, a arqueologia em terras rondonienses é ainda quase totalmente ausente, a única pesquisa de maior fôlego existente sendo o trabalho de Eurico Theofilo Miller (2007[1983]) na região do Alto Médio Guaporé (Rondônia e Mato Grosso), e nas bacias do alto Madeira e do JiParaná (a bibliografia está sistematizada em Miller 2009, 109-111). Miller vem buscando integrar seus achados arqueológicos com as pesquisas em etnologia, história e linguística na região, sustentando as hipóteses originalmente formuladas por Aryon Rodrigues acerca da origem dos Tupí nesta zona (Miller 2009). Novos trabalhos em arqueologia devem aumentar nossa compreensão do passado remoto da região do vale do rio Ji-Paraná (Cruz 2008; Zimpel Neto, 2009). Entretanto, a quase completa ausência de dados arqueológicos para o restante da "Grande Rondônia" não permite conhecer muitos dos processos sociais e históricos anteriores ao contato, e nem integrar a região às sínteses arqueológicas que foram e vêm sendo elaboradas para a Amazônia em particular, e para o território brasileiro em geral (Roosevelt 1992; Fausto 2000). Da mesma forma, a integração entre os dados linguísticos, arqueológicos e antropológicos que já está em andamento em outras regiões das terras baixas, como no Xingu (Heckenberger 2005), com resultados intrigantes - ainda está longe de poder ser efetuada em Rondônia.

De fato, portanto, o que se deve ressaltar é que o conhecimento antropológico das populações indígenas de língua Tupí em Rondônia depende, e muito, do trabalho que vem sendo realizado pelos linguistas - não querendo dizer, evidentemente, que isso seja um problema. Penso, por exemplo, nas já citadas proposições de Aryon Dall'Igna Rodrigues a respeito das relações historicamente verificáveis entre diversas populações a partir do estudo das línguas indígenas, e que alteraram substantivamente a maneira de a etnologia olhar para esta região etnográfica (cf. Urban 1992). Em escala menor, penso, também, nos corpora míticos e históricos coletados e reunidos por vários linguistas, como Ana Vilacy Galúcio (2006) para os Mekem-Sakyrabiat, Wany Sampaio et al. (2004) para os Amondáwa e Nilson Gabas Jr. (2002, 2009) para os Arára-Káro. Para as relações históricas entre vários grupos no interior de 
uma família linguística também temos, basicamente, o trabalho de competentes linguistas, como a reconstrução das relações entre as línguas/povos da família Ramaráma proposta por Nilson Gabas Jr. (2000), a sugestão, feita por Ana Suelly Câmara Cabral (2007) de uma possível relação entre os Kokáma e certos povos em Rondônia, como os Tuparí e os Karitiána (vínculo que merece estudos aprofundados), e o estudo de Wany Sampaio (2001) determinando as relações entre línguas/povos de língua Tupí-Kawahíwa. O mesmo se diga da organização de dicionários enquanto sínteses do conhecimento acumulado por determinada cultura - caso do dicionário Karitiana-Português-Inglês proposto por Luciana Storto (2002). Reafirmo que não estou, aqui, desqualificando o trabalho dos linguistas, que deve continuar e, sobretudo, crescer e adensar-se - e, inclusive, seguir coletando e analisando mitos, história, cultura. Apenas estou sugerindo que a intervenção do conhecimento antropológico deverá diversificar as formas de coleta e análise deste material, multiplicando os conhecimentos sobre cada um desses povos e das relações entre eles.

Dito tudo isso, ressaltamos um quadro de conhecimento etnológico ainda muito incipiente e fragmentário a respeito dos povos e culturas indígenas da região que estamos denominando "Grande Rondônia". É chegada, então, a hora das proposições.

\section{Por que pesquisar os Tupí na "Grande Rondônia"?}

A fantástica diversidade dos povos, culturas e histórias indígenas na "Grande Rondônia" deve, por si só, ser motivo suficiente para o interesse antropológico/etnológico nesta região em particular. Desvendar as origens desta diversidade e as dinâmicas internas a ela - incluindo suas relações com blocos populacionais etnográficos culturais vizinhos, indígenas e não-indígenas - deve ser um estímulo básico, que permita retirar da obscuridade essa imensa área do mapa etnográfico das terras baixas sulamericanas e integrá-la ao panorama que vem sendo elaborado, com maior ou menor densidade, para outras partes da Amazônia e do continente. Desta forma, a carência de estudos e pesquisas sobre as culturas na região constitui-se como um segundo motivo para o incremento da intervenção de antropólogos nos debates regionais. As sugestões apontadas pelos linguistas e arqueólogos - notadamente aquelas feitas por Aryon Rodrigues na linguística e a discussão desses dados a partir da arqueologia por Eurico Miller - constituem materiais importantes que destacam variadas linhas de investigação possíveis e apontam para certas convergências que não apenas 
poderão enriquecer os dados provenientes das pesquisas etnológicas, como estes deverão iluminar aqueles.

Haveria, ainda, por fim, uma razão teórica mais precisa para o interesse nesta área etnográfica que delimitamos. Com efeito, no prefácio à edição portuguesa do livro de Patrick Menget sobre os Ikpeng (Menget 2001), Eduardo Viveiros de Castro apontou para a importância do estudo etnográfico e etnológico da imensa região limítrofe entre a Amazônia e o Brasil Central grosso modo compreendida entre o alto Xingu, a leste, e o estado de Rondônia/ norte do estado de Mato Grosso, a oeste, onde as sociedades - como no caso dos Ikpeng (Txicão) - parecem combinar, de diferentes maneiras, aspectos sociológicos e cosmológicos de ambos os "perfis típicos" encontrados entre os povos amazônicos e os centro-brasileiros. Esta combinação, segundo Viveiros de Castro (2001:10-11), parece ser, na verdade, efeito do largo desconhecimento que ainda pesa sobre as populações nativas da área, "zona de transição entre as formações sociais da Amazônia sul-oriental (de dominância tupi-guarani) e as do Brasil Central (de dominância macro-jê)":

(...) A essa vasta região da Amazônia meridional falta, certamente, a homogeneidade linguística exibida pelos povos Jê ou pelos Tupí-Guaraní do Madeira e do Xingu-Tocantins; mas sua consistência morfológica e cosmológica (para além dos aspectos que podem ser ditos pan-amazônicos) parece-me digna de exame. A ideia de que ela constitui uma forma transicional - ou um amontoado heteróclito de formas transicionais - é possivelmente uma ilusão de ótica causada pela maior nitidez, nos quadros da etnologia atual, dos perfis amazônico típico (...) e "centro-brasileiro" (ou mais propriamente, jê e bororo) (...) (Viveiros de Castro 2001:11).

O que leva Viveiros de Castro a concluir, pelo menos para o caso Ikpéng, que talvez a área que define as fronteiras entre a floresta e o cerrado seja habitada por populações cujos sistemas sociais apresentariam a "forma canônica da socialidade amazônica" (Viveiros de Castro 2001, 11), casostipo a representar com perfeição os modos de organização sócio-cosmológica nativos da Amazônia.

Alguns anos antes, o mesmo Viveiros de Castro (1993) já destacara a possibilidade de se encontrar "uma ponte entre as duas regiões" - a saber, a Amazônia dravidiana e o Brasil Central (Viveiros de Castro 1993:149-150). Nesse artigo, o autor sinalizou a existência de "grupos da floresta tropical que mostram sistemas semelhantes aos centro-brasileiros", com três exemplos 
extraídos da "área cultural do Guaporé" (conforme Galvão 1979): Sirionó, Tupari (ambos Tupí) e Pakaá-Nova (Txapakúra). Esta observação novamente aponta para o interesse estratégico na investigação das cosmologias nativas desta região, e aqui poderíamos adicionar os grupos Tupí-Kawahíwa, povos de língua Tupí habitantes da floresta amazônica que, não obstante, apresentam sistemas de metades exogâmicas de feições tipicamente centro-brasileiras (cf. Peggion 2005).

A importância das pesquisas etnológicas nesta área que denominamos "Grande Rondônia", pode, portanto, contribuir de modo decisivo para a constituição de um quadro compreensivo mais geral sobre as formações sócio-cosmológicas nas terras baixas da América do Sul, permitindo aguçar o entendimento das articulações entre as culturas Amazônicas e as CentroBrasileiras, ou, em outros termos, entre os povos de língua Tupí e aqueles pertencentes ao tronco linguístico Macro-Jê. Nesse sentido, estamos sugerindo concentrar esforços nesta área que é o limite ocidental da área transicional Cerrado-Amazônia ${ }^{9}$, uma vez que suas faixas ocidental - os Karajá e Tapirapé ${ }^{10}$ e o alto Xingu - e central - os Sateré-Mawé e os Mundurukú apresentam boa quantidade e qualidade de pesquisas e possuem já um lugar consagrado na etnologia americanista.

Rondônia - a "Grande Rondônia", melhor dizendo, abarcando os vales do Guaporé/Mamoré/Beni e alto Madeira - representa, portanto, uma das zonas de crucial importância nesse quadro, não só por ser o limite ocidental da área transicional Cerrado-Amazônia, mas por apresentar, como já visto, uma notável diversidade cultural e linguística em um território relativamente restrito, fato destacado por muitos autores desde pelo menos Claude Lévi-Strauss (Lévi-Strauss 1948; Meireles 1984, 1989, 1991; Miller 2008 [1983]; Urban 1992; Crevels \& van der Voort 2008). A existência de dezenas de sociedades distintas, falando línguas de várias famílias linguísticas muito diversas, faz crer que o estudo antropológico da região dos afluentes meridionais do rio Madeira - Rondônia e áreas adjacentes - se reveste de um valor particular, tanto mais para o caso

\footnotetext{
${ }^{9}$ No mesmo texto que discutimos acima, em nota, Viveiros de Castro (1993:204, nota 22) sugere que os povos de língua Pano fariam a "transição entre as configurações amazônicas e as centro-brasileiras", o que implicaria em estendermos para o oeste os limites de nossa área de interesse até a fronteira do Brasil com o Peru. Como nosso foco aqui é Rondônia, não tenho condições de discutir detalhadamente esta possibilidade, que merece melhor investigação. Destaco, novamente, que os Páno também estão servidos por copiosa literatura, e existe relativamente consolidada uma rede de pesquisadores destes povos.

10 Nathalie Petesch (1993) sustenta que os Karajá também apresentam evidências de transição entre formas sociais Tupí e Jê; da mesma forma, Viveiros de Castro (1986:632) fala do "estilo "centrobrasileiro' da estrutura social e cerimonial Tapirapé" (Tupí).
} 
Tupí, uma vez que a região concentra grande número de culturas e línguas deste tronco, alguns estudos considerando Rondônia o centro mesmo de origem e dispersão das diferentes famílias linguísticas Tupí (Rodrigues 1964; Urban 1992). Tarefa urgente, uma vez que se trata de um conjunto de povos ainda parcamente conhecidos pela etnologia das terras baixas sulamericanas, muitos dos quais inclusive, e lamentavelmente, ameaçados de desaparecimento pelo violento processo colonizador na região, que ainda se faz sentir em múltiplos eventos e variados contextos.

\section{Referências}

Araújo, Carolina Pucu. 2002. A dança dos possíveis: o fazer de si e o fazer do outro em alguns grupos Tupí. Dissertação de mestrado, Museu Nacional, Universidade Federal do Rio de Janeiro.

Brunelli, Gilio. 1985. "Bebe! Bebe!... Jikkoi! Les Zorós vont à la chasse". Recherches amérindiennes au Québec 15(3):45-57.

Brunelli, Gilio. 1987a. "Migrations, guerres et identités: faits ethnohistoriques zoró". Anthropologie et sociétés 11(3):149-172.

Brunelli, Gilio. 1987b. "La salud por medio de las plantas: etnobotánica zoró, Amazonía brasileña”. América Indígena 47(2):241-268.

Brunelli, Gilio. 1988a. "La santé passe par la bouche, mais les dieux n'ont pas de chair". Trabalho apresentado no 46ème Congrès International d'Américanistes, Amsterdam, 4-7 julho.

Brunelli, Gilio. 1988b. "Maîtres de l'invisible. Notes et réflexions sur le chamanisme tupi-mondé”. Recherches amérindiennes au Québec 18 (1-2):127-43.

Brunelli, Gilio. 1989. De los espiritus a los micróbios. Salud y cambio social entre los Zoró de la Amazonía brasileña. Quito/Roma: Abya-Yala/MLAL.

Brunelli, Gilio. 1990. "Crossing worlds in quest for answers: Zoró indians explain illness". In Ethnobiology: implications and applications (2 vols), organizado por Darrel Posey \& William Overal:141-146. Belém: Museu Paraense Emilio Goeldi.

Cabral, Ana Suelly A. C. 2007. "New observations on the structure of Kokáma/Omágwa”. In Language endangerment and endangered languages, edited by Leo Wetzels:365-379. Leiden: CNWS Publications.

Cardozo, Ivaneide. 2006. "TI Igarapé Lourdes: etnozoneamento e gestão". In Povos Indígenas no Brasil - 2001/2005:603-606. São Paulo: Instituto Socioambiental. 
Cartagenes, Rosa \& Lobato, João Carlos. 1991. “À espera do desastre”. In Povos indígenas no Brasil 1987/88/89/90:445-446. São Paulo: Centro Ecumênico de Documentação e Informação.

Caspar, Franz. 1952. Tupari: unter indios im urwald brasiliens. S.1.: Friedr. Vieweg \& Sohn Braunschweig.

Caspar, Franz. 1953a. Tupari: entre os indios, nas florestas brasileiras. São Paulo: Melhoramentos.

Caspar, Franz. 1953b. "Some sex beliefs and practices of Tupari Indians (Western Brazil)". Revista do Museu Paulista, Nova Série, volume III:201-248.

Caspar, Franz. 1955a. "A expedição de P. H. Fawcett a tribo dos Maxubi em 1914”. Anais do XXXI Congresso Internacional de Americanistas. São Paulo: Anhembi (volume 1).

Caspar, Franz. 1955b. "Um caso de desenvolvimento anormal da personalidade observado entre os Tupari". Anais do XXXI Congresso Internacional de Americanistas. São Paulo: Anhembi:121-126.

Caspar, Franz. 1956-1958. "Puberty rites among the Tupari Indians". Revista do Museu Paulista, Nova Série, volume X:141-154.

Caspar, Franz. 1975. Die Tuparí, ein Indianerstamm in Westbrasilien. Berlin: Walter de Gruyter.

Caspar, Franz. 1976 [1957] “A aculturação dos Tuparis”. In Leituras de Etnologia Brasileira, editado por Egon Schaden, 486-515. São Paulo: Companhia Editorial Nacional.

Castro, Andréa C. Oliveira. 1996. "Morte e a simbólica da reprodução social". Trabalho apresentado na $20^{\mathrm{a}}$. Reunião Brasileira de Antropologia, Salvador.

Chapelle, Richard. 1982. Os índios Cintas-Largas. São Paulo/Belo Horizonte: Edusp/Itatiaia.

CIMI-RO. 2002. Panewa especial. Porto Velho: Conselho Indigenista Missionário - Regional Rondônia.

Cloutier, Sophie. 1987. "Sang et interdit chez les Zorós d'Amazonie brésilienne". Cahiers du GRAL 26.

Cloutier, Sophie. 1988a. "Les instruments musicaux des Indiens zorópangueyen (Amazonie brésilienne)". Recherches amérindiennes au Québec XVIII (4):75-86. 
Cloutier, Sophie. 1988b. Une nouvelle éthique en rupture avec la tradition. La conversion des Indiens Zoró à l'évangélisme de la Mission Nouvelles Tribus. Dissertação de mestrado, Université de Montréal.

Coimbra Jr., Carlos. 1989. From shifting cultivation to coffee farming: the impact of change on the health and ecology of the Surui in the Brazilian Amazon. Ph.D. dissertation, Indiana University.

Cornwall, Ricardo. 2003. Os Jumas: a continuação da violenta redução dos Tupí. Madalena/CE: R.Cornwall.

Crevels, Mily \& Hein van der Voort. 2008. "The Guaporé-Mamoré region as a linguistic area". In From linguistic areas to areal linguistics, edited by P. Muysken, 151-179. Amsterdam: John Benjamins Publishing Company.

Cruz, Daniel G. da. 2008. Lar, doce lar? Arqueologia Tupí na bacia do JiParaná (RO). Dissertação de mestrado, MAE-USP.

Cypriano, Doris. 2007. "Almas, corpos e especiarias: a expansão colonial nos rios Tapajós e Madeira”. Pesquisas - Antropologia 65:5-170.

Dal Poz Neto, João. 1991. No país dos Cinta Larga: uma etnologia do ritual. Dissertação de mestrado, Universidade de São Paulo.

Dal Poz Neto, João. 1993. "Homens, animais e inimigos: simetrias entre mito e rito nos Cinta Larga". Revista de Antropologia 36:177-206.

Dal Poz Neto, João. 1998. "Os ritos da identidade: um estudo das relações étnicas nos Cinta Larga". In Modelos e processos: Ensaios de etnologia indígena, organizado por Edir Pina de Barros, 149-226. Cuiabá: EdUFMT.

Dal Poz Neto, João. 2004. Dádivas e dívidas entre os Cinta-Larga. Tese de doutorado, UNICAMP.

Dal Poz Neto, João. 2010. "Dinheiro e reciprocidade nos Cinta-Larga: notas para uma economia política na Amazônia meridional”. Sociedade e Cultura 13(1):11-23.

Ermel, Priscilla. 1988. O sentido mítico do som: ressonâncias estéticas da música tribal dos índios Cinta-Larga. Dissertação de mestrado, PUC-SP.

Fausto, Carlos. 2000. Os índios antes do Brasil. Rio de Janeiro: Jorge Zahar Editor.

FOIRN \& ISA. 2000. Mapa-livro dos Povos Indígenas do alto e médio rio Negro. São Gabriel da Cachoeira: FOIRN; São Paulo: Instituto Socioambiental; Brasília: MEC-SEF. 
Forseth, Elisabeth \& Lars Lovold. 1991. "Os índios e a hidrelétrica JiParaná”. In Povos indígenas no Brasil 1987/88/89/90:428-434. São Paulo: Centro Ecumênico de Documentação e Informação.

Franchetto, Bruna \& Michael Heckenberger (orgs.). 2001. Os povos do alto Xingu: história e cultura. Rio de Janeiro: Ed. da UFRJ.

Freitas, Laura Perez. 1996. Changement social et santé chez les TupiMonde de Rondonia (Brésil). Dissertação de mestrado, Université de Paris X.

Gabas Jr., Nilson. 2000. "Genetic relationships within the Ramaráma family of the Tupí stock (Brazil)". In: Ensayos sobre lenguas indigenas de las tierras bajas de Sudamérica. Contribuciones al $49^{\circ}$ Congreso Internacional de Americanistas en Quito 1997, editado por Hein van der Voort \& S. van de Kerke, 71-82. Leiden: Research School of Asian, African, and American Studies (CNWS).

Gabas Jr., Nilson. (com narradores Arara, orgs.). 2002. Mây yamât Kanã xet pég xawero ma'i kanãy 'mãm-História dos Arara no tempo do contato com os brancos. Belém: MPEG.

Gabas Jr., Nilson. (com Sebastião Kara'yã Péw Arara, orgs.). 2009. Mitos Arara. Belém: MPEG.

Galucio, Ana Vilacy (org.). 2006. Narrativas tradicionais Sakurabiat Mayãp Ebõ. Belém: MPEG.

Galvão, Eduardo. 1979. “Áreas culturais indígenas do Brasil:1900-1959”. In Encontro de sociedades: índios e brancos no Brasil, 193-228. Rio de Janeiro: Paz \& Terra.

Gondim, Joaquim. 2001 [1924]. A pacificação dos Parintintim: Koró de iuirapá. Manaus: Edições do Governo do Estado.

Heckenberger, Michael. 2005. The power of ecology: culture, place, and personhood in the Southern Amazon, A.D. 1000-2000. London: Routledge.

Holmberg, Allan. 1969. Nomads of the long bow: the Siriono of Eastern Bolivia. Garden City: Natural History Press.

ISA. 2006. Povos indígenas no Brasil - 2001/2005. São Paulo: Instituto Socioambiental.

Junqueira, Carmen. S/d. "In the path of Polonoroeste: endangered peoples of Western Brazil - Os Cinta-Larga". Cultural Survival Occasional Papers 6:55-8. 
Junqueira, Carmen. 1984-85. "Os Cinta-Larga". Revista de Antropologia 27/28:213-232.

Junqueira, Carmen. 1984. "Sociedade e cultura: os Cinta-Larga e o exercício do poder do Estado". Ciência e Cultura 36(8):1284-1287.

Junqueira, Carmen. 2002. Sexo e desigualdade entre os Kamaiurá e os Cinta Larga. São Paulo: Olho d'Água/Capes.

Kracke, Waud. 1978. Force and persuasion: leadership in an Amazonian society. Chicago: University of Chicago Press.

Kracke, Waud. 1984. "Kagwahiv moieties: form without function?". In: Marriage patterns in Lowland South America, edited by Ken Kensinger, 99-124. Urbana: University of Illinois Press.

Kracke, Waud. 1990a. "El sueño como vehículo del poder shamánico: interpretaciones culturales y significados personales de los sueños entre los Parintintin". In: Antropología y experiencias del sueño, coordinado por Michel Perrin, 145-158. Quito/Roma: Abya-Yala/MLAL.

Kracke, Waud. 1990b. "Don't let the piranha bite your liver: Kagwahiv food taboos". In: The psychoanalytic study of society, edited by L.Boyer \& S.Hillside, 205-246. New Jersey: The Analytic Press.

Kracke, Waud. 1992. "He who dreams: the nocturnal source of healing power in kagwahiv shamanism". In Portals of power: shamanism in South America, edited by J. Langdon \& G.Baer, 127-148. Albuquerque: University of New Mexico Press.

Kracke, Waud. 2007. “A posição histórica dos Parintintín na evolução das culturas Tupí-Guarani”. In Línguas e culturas Tupí, organizado por A. D. Rodrigues \& A.S.C.Cabral, 23-35. Brasília: Editora Curt Nimuendaju/ LALI-UnB.

Kurovski, Angela. 2005. Anfitriões guerreiros: um estudo sobre rivalidades e generosidade entre os Kagwahiwa Parintintim. Dissertação de mestrado, UFPR.

Landin, David. 1979. "Some aspects of Karitiana food economy". Separata dos Arquivos de Anatomia e Antropologia 4:227-241.

Landin, Rachel. 1985. "Nature and culture in four Karitiana legends". In Five Amazonian Studies on world view and culture change, edited by William Merrifield, 59-69. Dallas: International Museum of Cultures.

Landin, Rachel. 1989. Kinship and naming among the Karitiana of Northwestern Brazil. Master thesis, University of Texas. 
Leonel, Mauro. 1996. Etnodicéia Uruéu-au-au. São Paulo: Edusp/IAMÁ/ FAPESP.

Lévi-Strauss, Claude. 1948a. "The tribes of the right bank of the Guaporé river". In Handbook of South American Indians, volume III, edited by Julian Steward, 370-379. Washington: Smithsonian Institution.

Lévi-Strauss, Claude. 1948b. "The Tupí Cawahib". In Handbook of South American Indians, volume III, edited by Julian Steward, 299-305. Washington: Smithsonian Institution.

Lévi-Strauss, Claude. 1996 [1955]. Tristes trópicos. São Paulo: Cia. das Letras.

Lovold, Lars. 1980. Through mythical eyes: the traditional world view of the Gavião and the Zoró Indians of Brazil. Oslo: Institute of Social Anthropology/ International Peace Research Institute.

Lovold, Lars. 1987. "First he locked them in: a creation myth among the Gavião and the Zoró indians of Brazil". In Native and Neighbors in Indigenous South America, edited by H.Skar \& F.Salomon, 417-442. Gothenburg: Göteborgs Etnografiska Museum.

Lúcio, Carlos Frederico. 1996. Sobre algumas formas de classificação social: etnografia sobre os Karitiana de Rondônia (Tupi-Arikém). Dissertação de mestrado, UNICAMP.

Lovold, Lars. 1998. "Heróis civilizadores, demiurgos sociais: algumas considerações sobre genealogia, mito e história entre os Caritianas (tupiariqueme)". Mosaico - Revista de Ciências Sociais 1(1):39-67.

Meireles, Denise Maldi. 1984. Populações indígenas e a ocupação histórica de Rondônia. Monografia de conclusão de curso, UFMT.

Meireles, Denise Maldi. 1989. Guardiães da fronteira. Rio Guaporé, século XVIII. Petrópolis: Vozes.

Meireles, Denise Maldi. 1991. "O complexo cultural do marico: sociedades indígenas dos rios Branco, Colorado e Mequens, afluentes do médio Guaporé". Boletim do Museu Paraense Emilio Goeldi - Série Antropologia 7(2):209-269.

Melatti, Júlio César. S/d. "Índios da América do Sul - áreas etnográficas". Acesso em set./2010. http://e-groups.unb.br/ics/dan/juliomelatti/ias.htm.

Menéndez, Miguel. 1981-82. "Uma contribuição para a etno-história da área Tapajós-Madeira". Revista do Museu Paulista, N.S. XXVIII: 289-388. 
Menéndez, Miguel. 1984-85. "Contribuição ao estudo das relações tribais na área Tapajós-Madeira”. Revista de Antropologia 27-28:271-286.

Menéndez, Miguel. 1987. “A presença do branco na mitologia Kawahiwa: história e identidade de um povo Tupi”. Studi e Materiali di Storia delle Religioni 53(1):75-97.

Menéndez, Miguel. 1989. Os Kawahiva: uma contribuição ao estudo dos Tupi Centrais. Tese de doutorado, Universidade de São Paulo.

Menéndez, Miguel. 1992. “A área Madeira-Tapajós: situação de contato e relação entre colonizador e indígenas". In História dos índios no Brasil, organizado por M. Carneiro da Cunha, 281-296. São Paulo: FAPESP/ SMC/Cia. das Letras.

Menget, Patrick. 2001. Em nome dos outros: classificação das relações sociais entre os Txicáo do Alto Xingu. Lisboa: Museu Nacional de Etnologia/Assírio \& Alvim.

Miller, Eurico Theófilo. 2007 [1983]. História da cultura indígena do Alto Médio-Guaporé: Rondônia e Mato Grosso. Porto Velho: Edufro.

Miller, Eurico Theófilo. 2009. “A cultura cerâmica do tronco Tupí no alto Ji-Paraná, Rondônia - Brasil”. Revista Brasileira de Linguística Antropológica 1(1):35-136.

Mindlin, Betty. 1981. "The Suruí”. Cultural Survival Occasional Papers 6: 53-4.

Mindlin, Betty. 1984a Os Suruí de Rondônia. Tese de doutorado, PUC-SP.

Mindlin, Betty. 1984b. "Comunitário ou coletivo: um caso tribal". Revista de Administração de Empresas 24(3):87-92.

Mindlin, Betty. 1984-85. "Os Suruí de Rondônia: entre a floresta e a colheita". Revista de Antropologia 27-28:203-211.

Mindlin, Betty. 1985. Nós Paiter: os Suruí de Rondônia. Petrópolis: Vozes.

Mindlin, Betty. 1989. "Iabadai Surui will not forget how the lumbermen killed Iabner". IWGIA Newsletter 58:21-31.

Mindlin, Betty. 1990. "Peixoté, a casa dos espíritos". Bric a Brac, s.n:55-56.

Mindlin, Betty. 1992. "Amor e ruptura na aldeia indígena”. In Amor, casamento e separação, organizado por I.Porchat. São Paulo: Brasiliense.

Mindlin, Betty. 1993a. "Medicina indígena e assistência médica: comentário sobre o Projeto de Saúde Suruí de Rondônia". Boletim da ABA 14:9-11. 
Mindlin, Betty. 1993b. Tuparis e Tarupás: narrativas dos índios Tuparis de Rondônia. São Paulo: Brasiliense/Edusp/IAMÁ.

Mindlin, Betty. 1994. "O aprendiz de origens e novidades: o professor indígena, uma experiência de escola diferenciada". Estudos Avançados 8(20):233-253.

Mindlin, Betty. 1995a. Unwritten stories of the Surui indians of Rondônia. Austin: Institute of Latin American Studies (Ilas Special Publication).

Mindlin, Betty. 1995b. Antologia de mitos dos povos Ajuru, Arara, Arikapu, Aruá, Kanoe, Jabuti e Makurap. São Paulo: IAMÁ.

Mindlin, Betty. 1996. Vozes da origem, estórias sem escrita: narrativas dos indios Surui de Rondônia. São Paulo: Ática/IAMÁ.

Mindlin, Betty. 1997. Moqueca de maridos: mitos eróticos. Rio de Janeiro: Record/Rosa dos Tempos.

Mindlin, Betty. 1999. Terra grávida. Rio de Janeiro: Record/Rosa dos Ventos.

Mindlin, Betty. 2001. O couro dos espíritos: namoro, pajés e cura entre os indios Gavião-Ikolen de Rondônia. São Paulo: SENAC/Terceiro Nome.

Mindlin, Betty. 2006a. Diários da floresta. São Paulo: Terceiro Nome.

Mindlin, Betty. 2006b. Mitos indígenas. São Paulo: Ática.

Mindlin, Betty. 2010. "A carne insaciável: um passeio por mitos tupi”. In Linguas e culturas Tupí, volume 2, organizado por A.S.C. Cabral, A.D. Rodrigues \& F.B. Duarte, 161-174. Campinas/Brasília: Editora Curt Nimuendajú/LALI-UnB.

Moser, Liliam. 1993. Os Karitiana e a colonização recente em Rondônia. Monografia de bacharelado, Universidade Federal de Rondônia.

Nimuendaju, Curt. 1924. "Os índios Parintintin do rio Madeira”. Journal de la Socièté des Américanistes 16 (n.s.):201-278.

Nimuendaju, Curt. 1948. "The Cawahib, Parintintin and their neighbors." In Handbook of South American Indians, volume III, edited by Julian Steward, 387-397. Washington: Smithsonian Institution.

Nóbrega, Renata da Silva. 2008. Contra as invasões bárbaras, a humanidade: a luta dos Arara (Karo) e dos Gavião (Ikólóehj) contra os projetos hidrelétricos do rio Machado, em Rondônia. Dissertação de mestrado, UNICAMP.

Noelli, Francisco. 1998. "The Tupi: explaining origin and expansions in terms of archaeology and of historical linguistics". Antiquity 72 (277): 648-663. 
Peggion, Edmundo. 1996. Forma e função: uma etnografia do sistema de parentesco Tenharim (Kagwahív-AM). Dissertação de mestrado, UNICAMP.

Peggion, Edmundo. 1996. "Estratégia matrimonial e sociabilidade em um grupo Tupi: os Tenharim do Amazonas". In A temática indígena na escola, organizado por Aracy Lopes da Silva \& Luiz D.B. Grupioni. Brasília: MEC/MARI/Unesco.

Peggion, Edmundo. 1998. "Os procedimentos na identificação de terras indígenas: relato de uma experiência". Boletim da ABA 29:12-4.

Peggion, Edmundo. 2004. "Alianças e facções: a organização política dos Kagwahiwa da Amazônia”. Estudios Latinoamericanos - Varsovia 22.

Peggion, Edmundo. 2005. Relações em perpétuo desequilíbrio: a organização dualista dos Kaguahiwa da Amazônia. Tese de doutorado, Universidade de São Paulo.

Peggion, Edmundo. 2007a. "Ritual e vida cotidiana no sul do Amazonas: os Tenharim do rio Marmelos". Perspectivas (São Paulo) 29:149-168.

Peggion, Edmundo. 2007b. "A classe dos nomes: a onomástica Amondawa (Kagwahiva/RO). In Linguas e culturas Tupí, organizado por A.D. Rodrigues \& A.S.C. Cabral, 123-130. Brasília: Editora Curt Nimuendaju/LALI-UnB.

Peggion, Edmundo. 2008. "La metà esogamiche dei Tenharim del rio Marmelos: um sistema in perpetuo disequilibrio". In Amazzonia indígena 2007: resoconti di ricerca sul campo, editado por G. Bamonte \& P. Bollettin, 159-169. Roma: Bulzoni Editore.

Peggion, Edmundo. 2009. "Uma etnografia dei popoli Kagwahiva dell'Amazzonia". In Ricerca sul campo in Amazzonia 2008: resoconti di studio, editado por P. Bollettin \& U.Mondini, 68-80. Roma: Bulzoni Editore.

Pereira, Nunes. 1980. “Área cultural Tapajós-Madeira, estado do Amazonas". In Moronguêta: um decameron indígena (volume 2), 523 680. Brasília/Rio de Janeiro: INL/Civilização Brasileira.

Pereira, Nunes. 2007. Experiências e estórias de Baíra - o grande burlão. Manaus: Valer.

Petesch, Nathalie. 1993. “A trilogia Karajá: sua posição intermediária no continuum Jê-Tupi”. In Amazônia: Etnologia e História Indígena, organizado por Eduardo Viveiros de Castro \& Manuela Carneiro da Cunha, 365-382. São Paulo: NHII-USP/FAPESP. 
Pinto, Nicole Soares. 2009. Do poder do sangue e da chicha: os Wajuru do Guaporé (Rondônia). Dissertação de mestrado, UFPR.

Riester, Jürgen. 1977. Los Guarasug'we: crónica de sus últimos dias. Santa Cruz de la Sierra: APCOB.

Rodrigues, Aryon Dall'Igna. 1964. “A classificação do tronco linguístico Tupí”. Revista de Antropologia 12:99-104.

Rodrigues, Aryon Dall'Igna. 1986. Línguas brasileiras: para o conhecimento das línguas indigenas. São Paulo: Edições Loyola.

Rodrigues, Aryon Dall'Igna. 2007. “Tupí languages in Rondônia and in eastern Bolivia". In Language endangerment and endangered languages, edited by Leo Wetzels, 355-363. Leiden: CNWS Publications.

Rondon, Cândido Mariano da Silva. 1916. Missão Rondon: apontamentos sobre os trabalhos realizados pela Commissão de Linhas Telegraphicas Estrategicas de Matto-Grosso ao Amazonas. Rio de Janeiro: Typographia do Jornal do Commercio.

Roosevelt, Anna. 1992. “Arqueologia Amazônica”. In História dos índios no Brasil, organizado por Manuela Carneiro da Cunha, 53-86. São Paulo: FAPESP/SMC/Cia. das Letras.

Roquette-Pinto, Edgar. 1935. Rondônia. São Paulo: Cia. Editora Nacional.

Sampaio, Wany. 2001. As línguas tupi-kawahib: um estudo sistemático filogenético. Tese de doutorado, Universidade Federal de Rondônia.

Sampaio, Wany; Silva, Vera da \& Valdemir Miotello (orgs.). 2004. Mitos Amondawa. Porto Velho: Edufro.

Santos, Ricardo Ventura. 1991. Coping with change in native Amazonia: a bioanthropological study of the Gavião, Surui, and Zoró, Tupi-Mondé speaking societies from Brazil. Ph.D. dissertation, Indiana University.

Santos-Granero, Fernando \& Frederica Barclay (orgs.). 1994. Guía etnográfica de la Alta Amazonía (Volume I). Quito: FLACSO.

Schettino, Marco P.. 2003. “Áreas etnográficas: proposta de reestruturação do Departamento de Identificação e Delimitação com base na atuação em áreas etnográficas". Terra dos índios: revista eletrônica sobre questão fundiária indigena no Brasil, ano 1, n. 00, DAF-FUNAI, acesso em mai./2003. www.funai.gov.br/ultimas/e_revista/index.htm.

Silva, Vera da. 1997. Amondava: uma história de perdas. Ouro Preto d'Oeste: GAPI.

Snethlage, Emilia. 1937. Atiko Y, meine Erlebnisse bei den Indianern des Guaporé. Berlim: Klinkhardt \& Biermann Verlag. 
Snethlage, Emilia. 1939. Musikinstrumente der Indianer des

Guaporégebietes. Baesler-Archiv, Beiträge zur Völkerkunde, Beiheft X. Berlin: Dietrich Reimer - Andrews \& Steiner.

Snethlage, Emilia. 1987. No longer nomads: the Sirionó revisited. Lanham/ MD: Hamilton Press.

Snethlage, Emilia. 1989. Yuqui: forest nomads in a changing world. Fort Worth: Holt, Rinehart and Winston.

Snethlage, Emilia. 2006. "One step forward, two steps back: the Sirionó and Yuquí community forestry projects in the Bolivian Amazon". Human Organization 65(2):156-166.

Storto, Luciana. 2002. "Dicionário preliminar Karitiana-Português-Inglês: um produto do processo de educação e manutenção da cultura entre os Karitiana". Linguas indígenas brasileiras: fonologia, gramática e história. Atas do I Encontro Internacional do Grupo de Trabalho sobre Linguas Indígenas da ANPOLL, tomo I. Belém: ANPOLL/EdUFPA.

Stearman, Allyn. 1984. "The Yuquí connection: another look at Sirionó deculturation". American Anthropologist 86:3630-3650.

Tempesta, Giovana. 2009. Travessia de banzeiros: historicidade e organização sociopolítica apiaká. Tese de Doutorado, Universidade de Brasília.

Urban, Greg. 1992. “A história da cultura brasileira segundo as línguas nativas". In História dos índios no Brasil, organizado por Manuela Carneiro da Cunha, 87-102. São Paulo: FAPESP/SMC/Cia. das Letras.

Vander Velden, Felipe. 2004. Por onde o sangue circula: os Karitiana e a intervenção biomédica. Dissertação de mestrado, UNICAMP.

Vander Velden, Felipe. 2005. "Corpos que sofrem: uma interpretação Karitiana dos eventos de coleta de seu sangue". Documento de Trabalho - CESIR/Unir/ENSP 12:3-42.

Vander Velden, Felipe. 2007. "Circuitos de sangue: corpo, pessoa e sociabilidade entre os Karitiana”. Habitus 5:275-300.

Vander Velden, Felipe. 2008. "O gosto dos outros: o sal e a transformação dos corpos entre os Karitiana no sudoeste da Amazônia”. Temáticas 31:11-41.

Vander Velden, Felipe. 2010a. Inquietas companhias: sobre os animais de criação entre os Karitiana. Tese de doutorado, UNICAMP.

Vander Velden, Felipe. 2010b. "De volta para o passado: territorialização e 'contraterritorialização' na história karitiana”. Sociedade e Cultura 13: $55-65$. 
Vilaça, Aparecida. 2006. Quem somos nós: os Wari'encontram os brancos. Rio de Janeiro: Editora UFRJ.

Viveiros de Castro, Eduardo. 1986. Araweté: os deuses canibais. Rio de Janeiro: Jorge Zahar Editor/Anpocs.

Viveiros de Castro, Eduardo. 1993. "Alguns aspectos da afinidade no dravidianato amazônico". In: Amazônia: Etnologia e História Indígena, organizado por Eduardo Viveiros de Castro \& Manuela Carneiro da Cunha, 149-210. São Paulo: NHII-USP/FAPESP.

Viveiros de Castro, Eduardo. 2001. Apresentação a Em nome dos outros: classificação das relações sociais entre os Txicáo do Alto Xingu, de Patrick Menget, 7-13. Lisboa: Museu Nacional de Etnologia/Assírio \& Alvim.

Zimpel Neto, Carlos. 2009. Na direção das periferias extremas da Amazônia: arqueologia na bacia do rio Jiparana, Rondônia. Dissertação de mestrado, MAE-USP. 
